\title{
Developing a screw conveyor in radio frequency systems to improve heating uniformity in granular products
}

\author{
Hongxue Zhou ${ }^{1}$, Shaojin Wang ${ }^{1,2^{*}}$ \\ (1. College of Mechanical and Electronic Engineering, Northwest A\&F University, Yangling 712100, Shaanxi, China; \\ 2. Department of Biological System Engineering, Washington State University, 213 L.J. Smith Hall, Pullman, WA 99164-6120, USA)
}

\begin{abstract}
Radio frequency (RF) treatments have been increasingly studied due to the rapid heating, deep power penetration depth and high energy efficiency. However, the major challenges for commercial RF applications are non-uniform and run-away heating. The purpose of this study was to improve RF heating uniformity in three granular products (soybean, corn, and peanut) using a custom-made screw conveyor with sample movement and mixing. The results showed that soybean, corn and peanut samples in the screw conveyor were RF heated in a similar heating rate under the selected electrode gap and screw rotation speed, and the variations between the highest and lowest temperatures in the three samples were all clearly reduced as compared to the stationary treatments. The RF heating uniformity index was also reduced for soybean, corn, and peanut during and after the RF treatment. Therefore, the screw conveyor could improve RF heating uniformity due to stable, continuous, uninterrupted movement and mixing of samples. The small-scale screw conveyor used in RF systems would provide a solid basis for further large-scale industrial applications.
\end{abstract}

Keywords: radio frequency (RF), screw conveyor, heating uniformity, movement, mixing DOI: $10.25165 /$ j.ijabe.20191203.4227

Citation: Zhou H X, Wang S J. Developing a screw conveyor in radio frequency systems to improve heating uniformity in granular products. Int J Agric \& Biol Eng, 2019; 12(3): 174-179.

\section{Introduction}

Heating with radio frequency (RF) energy has been considered as a novel heating technology for postharvest baking ${ }^{[1,2]}$, cooking ${ }^{[3]}$, thawing $^{[4,5]}$, drying ${ }^{[6,7]}$, pasteurization ${ }^{[8,9]}$, enzyme inactivation ${ }^{[10]}$ and disinfestation ${ }^{[11]}$. Recently, RF treatments have been increasingly studied due to rapid heating, deep power penetration depth, and high energy efficiency ${ }^{[12-16]}$. However, heating uniformity is a major concern for applying RF systems to industrial applications $^{[17-19]}$.

The major challenges for commercial RF applications are non-uniform and run-away heating, such as overheating in corners and edges ${ }^{[20-23]}$. Many methods for improving the RF heating uniformity have been studied, such as hot air surface heating, conveyor movement, sample mixing ${ }^{[11,24-26]}$, changing the shape of foodstuff ${ }^{[27,28]}$ and using special material containers whose dielectric properties being similar to those of samples ${ }^{[29]}$. Among these methods, mixing is a very effective way to improve sample temperature distribution volumetrically ${ }^{[25]}$ since the conveyor belt provides the limited RF heating uniformity improvement only along movement direction ${ }^{[30,31]}$. Chen et al. ${ }^{[18]}$ simulated the RF heating uniformity under mixing conditions and proved the positive effect of mixing on improving sample temperature distributions. However, most applications of mixing were completed by turning off the RF system and taking out samples on the conveyor belt

Received date: 2018-03-08 Accepted date: 2019-03-20

Biographies: Hongxue Zhou, Master, research interest: radio frequency heating, Email: zhouhongxue11@126.com.

*Corresponding author: Shaojin Wang, PhD, Professor, research interest: processing and storage of agricultural products, disinfestation and pasteurization of postharvest products using radio frequency heating. College of Mechanical and Electronic Engineering, Northwest A \& F University, No. 22 Xinong Rd., Yangling 712100, Shaanxi, China. Tel: +86-29-87092319, Fax: +86-2987091737, Email: shaojinwang@nwsuaf.edu.cn. from the RF cavity ${ }^{[11,24-26]}$. This mixing method might seriously affect the efficiency and throughput of RF processing. Therefore, a reliable mechanical device is urgently needed to perform both moving and mixing during the RF heating.

The screw conveyor is mainly used in solid handling processes for practical transport applications, such as pharmaceutical production, food, and mineral processing ${ }^{[32-35]}$ due to its simple structure and reliable usability. The screw conveyor could achieve mixing during sample transport ${ }^{[36]}$. The effects of various process variables and mixing of a screw conveyor used for drying were studied by Waje et al. ${ }^{[32]}$ Qi et al. ${ }^{[35]}$ reported that the screw conveyor could achieve better effects of mixing for two kinds of granular products using the discrete element method and the effect of mixing was affected by screw pitch length and screw rotation speed in the transport process. Without applications in the literature so far, the screw conveyor could be used for movement and mixing of samples during the RF process. The effects of using the laboratory-scale screw conveyor on improving RF heating uniformity are required to be determined before industrial applications.

The objectives of this study were (1) to select the material and main parameters of the screw conveyor applied in the RF system, (2) to determine the electrode gap of the RF system and rotation speed of the screw conveyor for achieving the suitable RF heating rate in three representative granular products, such as soybean, corn, and peanut, and (3) to evaluate the sample temperature distribution and heating uniformity improvement at different sections and points during and after RF treatments.

\section{Material and methods}

\subsection{Materials and sample preparation}

Three granular products, soybean (Glycine mux L.), corn (Zea mays L.), and peanut (Arachis hypogea L.) were selected as representative samples and purchased from a local market in 
Yangling, Shaanxi, China. Table 1 shows the physical properties of these three samples collected from the literature. All samples including soybean, corn, and peanut in plastic bags were kept in a refrigerator (BD/BC-297KMQ, Midea Refrigeration Division, Hefei, China) at $3^{\circ} \mathrm{C} \pm 1^{\circ} \mathrm{C}$ before experiment. Samples were taken out of the refrigerator and put into an incubator (BSC-150, Boxun Industry \& Commerce Co., Ltd, Shanghai, China) to equilibrate at $25^{\circ} \mathrm{C} \pm 0.5^{\circ} \mathrm{C}$ for one day prior to the tests.

Table 1 Physical properties of three target granular samples at $25^{\circ} \mathrm{C}$

\begin{tabular}{|c|c|c|c|}
\hline \multirow{2}{*}{ Properties } & \multicolumn{3}{|c|}{ Sample } \\
\hline & Soybean & Corn & Peanut \\
\hline Diameter $/ \mathrm{mm}$ & $6.3 \pm 1.1$ & $11.4 \pm 1.3$ & $16.2 \pm 1.5$ \\
\hline Dielectric constant & $3.69^{\mathrm{a}}$ & $2.93^{\mathrm{b}}$ & $5.22^{\mathrm{c}}$ \\
\hline Dielectric loss factor & $0.28^{\mathrm{a}}$ & $0.18^{\mathrm{b}}$ & $0.61^{\mathrm{c}}$ \\
\hline
\end{tabular}

\subsection{RF heating system and screw conveyor}

A $27.12 \mathrm{MHz}, 6 \mathrm{~kW}$ pilot-scale free-running oscillator $\mathrm{RF}$ system (SO6B, Strayfield International, Wokingham, U.K.) with a hot air system $(6 \mathrm{~kW})$ and a screw conveyor $(4 \mathrm{~m} \times \varnothing 0.11 \mathrm{~m})$ was used for the heating experiment (Figure 1). A detailed description of the RF unit with hot air system can be found in Wang et al. ${ }^{[21]}$ The screw conveyor was designed and placed on the bottom electrode of the RF system. The samples got into the screw conveyor from the inlet feed at the left side were moved by a motor (ZXF1418-650, Zhejiang Unite Electrical Motor Co., Ltd., Yongkang, China) and finally arrived at the collecting container via the exit at the right side after transportation. The hot air at $70^{\circ} \mathrm{C}$ as the same target temperature of samples was used for surface heating of the screw conveyor to reduce the sample temperature loss during RF treatments. This target temperature was selected based on $10^{\circ} \mathrm{C}$ more than the thermal death one of controlling the most insects. The hot air was provided by an air distribution box under the bottom electrode with its speed of $1.6 \mathrm{~m} / \mathrm{s}$ measured by an anemometer (DT-880, China Everbest Machinery Industry Co., Ltd., Shenzhen, China) at $2 \mathrm{~cm}$ above the bottom electrode.

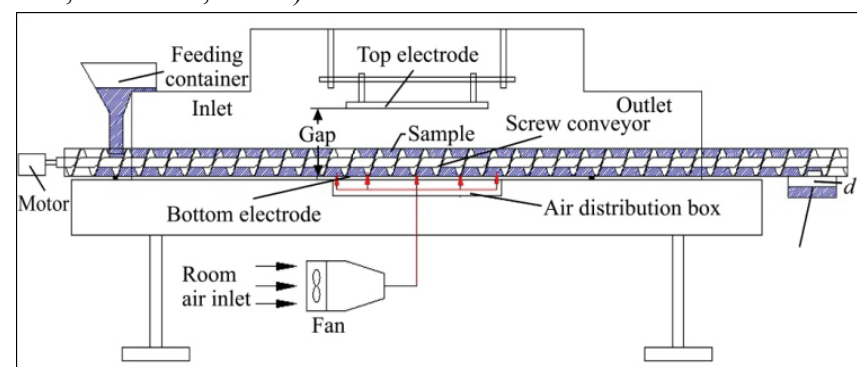

Note: Section $\mathrm{d}$ is for final collections of the RF treated samples in the screw conveyor.

Figure 1 Schematic view of the free running oscillator

27.12 MHz, $6 \mathrm{~kW}$ RF system showing the plate electrode, hot air system and screw conveyor

\subsection{Selecting the material and parameters of the screw conveyor}

The geometry of the single screw conveyor is shown in Figure 2 with the 6 points at each of three cross-sections ( $a, b$ and $c$ ) for sample temperature measurements. The screw conveyor included cylindrical wall and screw, which were respectively made by polyvinyl chloride and polyamide due to their better mechanical properties and thermal stabilities with low loss factor in RF systems. Three main parameters for designing the screw conveyor using the plastic materials include screw pitch $P$, shaft diameter $d$ and flight diameter $D$ (Figure 3). These three parameters directly influence the performance of the screw conveyor $^{[37]}$. The values of the three parameters were selected so as to meet the required rotation speed and achieve the required temperature after the RF treatments ${ }^{[34,37-39]}$.

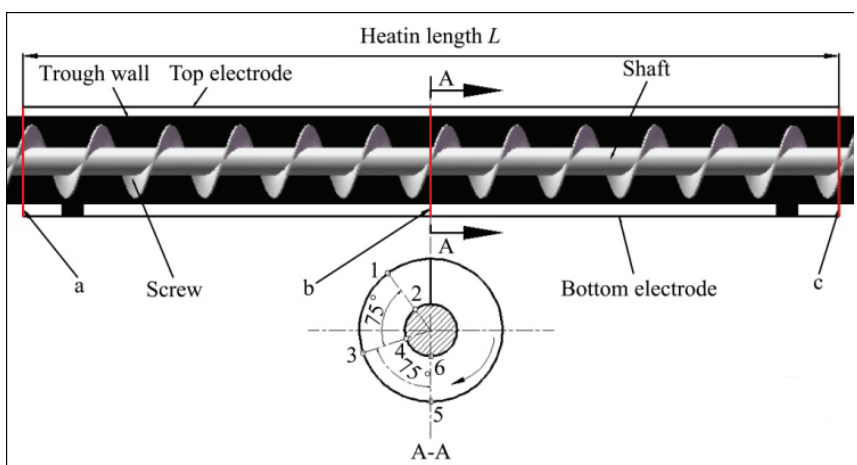

Figure 2 Measurement points (1-6) at each of three cross-sections $(\mathrm{a}, \mathrm{b}$ and $\mathrm{c})$ for sample temperature measurements in the screw conveyor

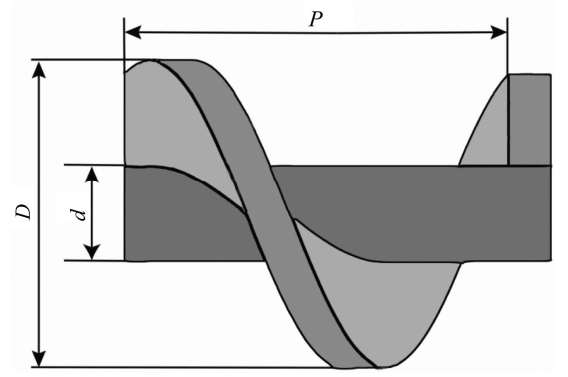

Figure 3 Schematic diagram of spiral structure for the screw conveyor with flight diameter $(D=10 \mathrm{~cm})$, shaft diameter $(d=4 \mathrm{~cm})$ and screw pitch $(P=8 \mathrm{~cm})$ (adapted from Qi et al. $\left.{ }^{[35]}\right)$

\subsection{Selecting electrode gap and screw rotation speed}

To determine the electrode gap of the RF system and screw rotation speed, soybean, corn, or peanut samples filled with the screw conveyor were placed on the bottom electrode to obtain a general relationship between electrode gaps and electric currents ( $I$, A) without movement and mixing. After RF heating was turned on, the control screen of the RF system displayed the anode electrical current being used and was immediately recorded when the electrode gap increased from $12 \mathrm{~cm}$ to $19 \mathrm{~cm}$ with a $1 \mathrm{~cm}$ interval. A detailed description of measurement could be found in Zhou et al. ${ }^{[24]}$ All tests were repeated three times. Based on the measured electric current, three electrode gaps of $12 \mathrm{~cm}, 13 \mathrm{~cm}$, and $14 \mathrm{~cm}$ were selected to further determine the temperature-time histories in RF treated samples with no arcing and fast heating rates. Under each of the three selected electrode gaps, the sample temperatures at 6 points of position $b$ (Figure 2) were recorded by a six-channel fiber-optic temperature sensor system (HQ-FTS-D120, Heqi Technologies Inc., Xian, China) with an accuracy of $\pm 0.5^{\circ} \mathrm{C}$. The time needed to heat the soybean, corn, and peanut samples from ambient temperature $\left(25^{\circ} \mathrm{C}\right)$ to target temperature $\left(70^{\circ} \mathrm{C}\right)$ was recorded. The final electrode gap was fixed based on the whole average heating rate $\left(4-6^{\circ} \mathrm{C} / \mathrm{min}\right)$ of samples. For the different samples, the corresponding electrode gaps were selected to achieve the similar effect of heating rates on the RF heating uniformity. The most suitable electrode gap was obtained based on the closest heating of the three samples. Then, the screw rotation speed during the RF heating was calculated by the following equation:

$$
\omega=\frac{L}{P t}
$$


where, $L$ is the heating length, $0.8 \mathrm{~m} ; P$ and $t$ are screw pitch (m), and heating time (s), respectively.

\subsection{RF heating procedure}

After the electrode gap and screw rotation speed were set up, the sample temperatures at 6 points in sections of $\mathrm{a}, \mathrm{b}$ and $\mathrm{c}$ (Figure 2) for initial, middle (stationary) and final stages were immediately measured by two type-T thermocouple thermometers (TMQSS-020-6, Omega Engineering Ltd., CT, USA). The detailed description of thermocouple thermometers can be found in Hou et al. ${ }^{[40]}$ Finally, the samples were quickly moved into the collecting container $(30 \mathrm{~cm} \times 22 \mathrm{~cm} \times 6 \mathrm{~cm})$ (Figure 4) as in the section $\mathrm{d}$ (Figure 1). The collected sample thickness was about $2 \mathrm{~cm}$ in the container. The surface temperature of the samples was immediately measured by a thermal imaging camera (DM63, Zhejiang Dali Technology Co., Ltd., Hangzhou, China) with an accuracy of $\pm 2^{\circ} \mathrm{C}$. Each thermal image took less than $2 \mathrm{~s}$. From each of the thermal images, 44250 individual surface temperature data points were collected over a sample surface temperature in the container and used for statistical analyses ${ }^{[41]}$. The detailed procedure and data treatment for thermal imaging can be found elsewhere ${ }^{[26,42,43]}$. The whole measurement process was completed by less than $1 \mathrm{~min}$. Each test was repeated three times.

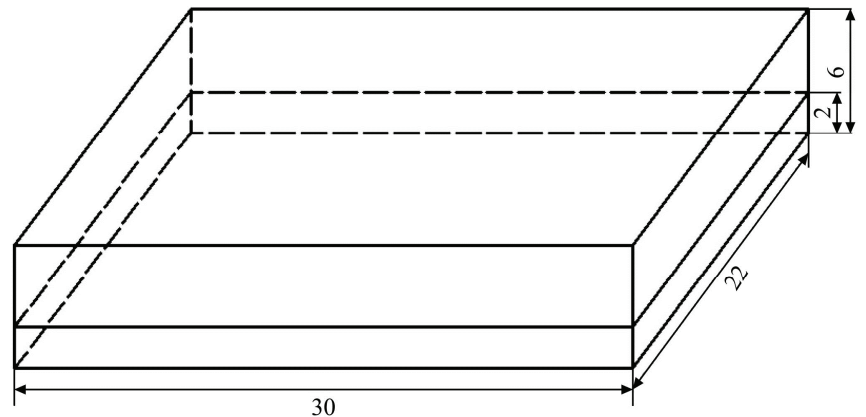

Figure 4 Collecting plastic container in the section $\mathrm{d}$ for sample temperature measurement (all dimensions are in $\mathrm{cm}$ )

\subsection{Heating uniformity evaluation}

Heating uniformity is a key factor in developing successful pasteurization and disinfestation protocols using RF energy. Heating uniformity index $(\lambda)$ has been proposed by Wang et al. ${ }^{[41,44]}$ to estimate temperature distributions of RF heated samples. This index $\lambda$ has been successfully used for evaluating RF heating uniformity in many different kinds of products, such as walnuts ${ }^{[45]}$, legumes ${ }^{[21]}$, lentils ${ }^{[46]}$, coffee beans ${ }^{[47]}$, almonds ${ }^{[48]}$, chestnuts $^{[10]}$, rice $\mathrm{e}^{[16,24,42,43]}$, peanut ${ }^{[29]}$, and corns ${ }^{[26]}$. Heating uniformity index is defined as the ratio of the rise in the standard deviation of sample temperatures to the rise in average sample temperatures during RF treatment and can be calculated by the following equation ${ }^{[44]}$ :

$$
\lambda=\frac{\sqrt{\sigma^{2}-\sigma_{0}^{2}}}{\mu-\mu_{0}}
$$

where, $\mu_{0}$ and $\mu$ are initial and final mean temperatures of sample, ${ }^{\circ} \mathrm{C} ; \sigma_{0}$ and $\sigma$ are initial and final standard deviations of sample temperatures over RF heating time, ${ }^{\circ} \mathrm{C}$, respectively. A smaller value represents better RF heating uniformity.

\subsection{Statistical analysis}

Mean values and standard deviations were calculated from the three replicates for each treatment. The mean values were separated with Tukey's method at a significance level of 0.05 using a Microsoft Excel variance procedure (Microsoft Office Excel, 2010).

\section{Results and discussion}

\subsection{Electric current under different electrode gaps}

The relationship between the electric current and the electrode gap is shown in Figure 5 when the screw conveyor was placed on the RF bottom electrode with or without samples. Without samples, the electric current was almost constant, around $0.35 \mathrm{~A}$, which was not affected by the electrode gap changes. With samples, the electric current decreased rapidly when the electrode gap increased from $12 \mathrm{~cm}$ to $15 \mathrm{~cm}$, and then decreased slowly when the electrode gap changed from $15 \mathrm{~cm}$ to $19 \mathrm{~cm}$. Similar trends were also found by other researchers ${ }^{[11,16,25,43]}$. These results would provide the basis for the following experiments to select the optimal electrode gap.

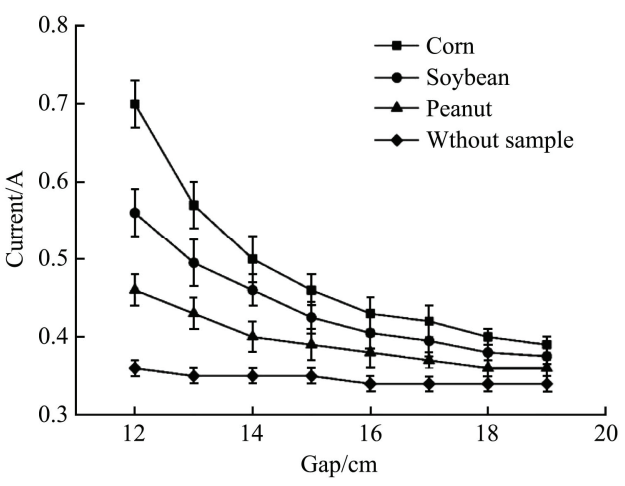

Figure 5 Electrical current of the RF system without and with three samples as a function of the electrode gap

\subsection{Determination of electrode gap and screw rotation speed}

Table 2 presents average and standard deviation of heating rates for soybean, corn, and peanut with electrode gaps of $12 \mathrm{~cm}$, $13 \mathrm{~cm}$, and $14 \mathrm{~cm}$ during RF heating. Heating rates in soybeans were $7.4^{\circ} \mathrm{C} / \mathrm{min}, 5.6^{\circ} \mathrm{C} / \mathrm{min}$ and $4.7^{\circ} \mathrm{C} / \mathrm{min}$ for the electrode gaps of $12 \mathrm{~cm}, 13 \mathrm{~cm}$, and $14 \mathrm{~cm}$, respectively. The heating rate increased with decreasing electrode gap. Short heating times corresponded to higher throughput, but heating uniformity could be negatively affected by rapid RF heating ${ }^{[11,26]}$. To obtain a better balance between throughput and heating uniformity, the electrode gap of $13 \mathrm{~cm}$ was selected for soybeans to achieve a suitable heating rate of $5.6^{\circ} \mathrm{C} / \mathrm{min}$ and used for further heating uniformity tests. Similarly, the electrode gaps of $14 \mathrm{~cm}$ and $12 \mathrm{~cm}$ were selected for corn and peanut to obtain heating rates of $5.7^{\circ} \mathrm{C} / \mathrm{min}$ and $5.8^{\circ} \mathrm{C} / \mathrm{min}$, respectively. These heating rates are similar to those used in milled rice $\left(5.8^{\circ} \mathrm{C} / \mathrm{min}\right)^{[24]}$, corn $\left(6.0^{\circ} \mathrm{C} / \mathrm{min}\right)^{[26]}$ and chestnut $\left(6.5^{\circ} \mathrm{C} / \mathrm{min}\right)^{[11]}$.

Table 2 Average heating rates $\left({ }^{\circ} \mathrm{C} / \mathrm{min}\right)$ under different electrode gaps for three samples without movement and mixing

\begin{tabular}{cccc}
\hline \multirow{3}{*}{ Sample } & \multicolumn{3}{c}{ Gap/cm } \\
\cline { 2 - 4 } & 12.0 & 13.0 & 14.0 \\
\hline Soybean & $7.4 \pm 0.4$ & $5.6 \pm 0.3$ & $4.7 \pm 0.3$ \\
Corn & $11.3 \pm 0.6$ & $8.5 \pm 0.5$ & $5.7 \pm 0.4$ \\
Peanut & $5.8 \pm 0.4$ & $4.7 \pm 0.3$ & $3.2 \pm 0.3$ \\
\hline
\end{tabular}

The screw rotation speed was estimated with three samples as listed in Table 3 together with total RF heating time and electrode gap. The speed of screw rotation determined by the heating rates and electrode length was about $1.2 \mathrm{r} / \mathrm{min}, 1.2 \mathrm{r} / \mathrm{min}$ and $1.3 \mathrm{r} / \mathrm{min}$ for soybean, corn, and peanut samples, respectively. Besides, about $8.0 \mathrm{~min}, 7.9 \mathrm{~min}$ and $7.8 \mathrm{~min}$ were needed to heat soybean, corn, and peanut samples from $25^{\circ} \mathrm{C}$ to $70^{\circ} \mathrm{C}$, respectively. These 
parameters could be further used in heating uniformity experiments.

Table 3 Electrode gaps and screw rotation speeds of three samples with movement and mixing

\begin{tabular}{cccc}
\hline Sample & Gap/cm & Heating time $/ \mathrm{min}$ & Rotation speed $\omega / \mathrm{r} \cdot \mathrm{min}^{-1}$ \\
\hline Soybean & 13.0 & 8.0 & 1.2 \\
Corn & 14.0 & 7.9 & 1.2 \\
Peanut & 12.0 & 7.8 & 1.3 \\
\hline
\end{tabular}

\subsection{Distribution of temperature inside the screw conveyer} after RF treatment

Table 4 lists the temperatures of three samples at 6 measurement points in 3 sections during RF treatments. The initial temperature distribution was uniform with small standard deviation of $0.2^{\circ} \mathrm{C}$ before RF heating. After RF heating under stationary conditions without moving and mixing, the sample temperatures were not uniform with a large standard deviation up to $3.6^{\circ} \mathrm{C}$. The temperature variations after RF heating were better in small particle size samples than in large ones ${ }^{[29]}$. Moving and mixing in the section $\mathrm{c}$ reduced the temperature variations in the three samples compared with the stationary condition in the section $\mathrm{b}$, which indirectly indicated the better RF heating uniformity after transportation by the screw conveyor. The surface temperatures (points 1,3 and 5) of three samples were lower than the internal ones (points 2, 4 and 6) in the sections $b$ and $c$ of the screw conveyor with or without movement and mixing. This trend was similar to that in RF heated apples ${ }^{[49]}$. However, this rule was contrary to hot water heating ${ }^{[50]}$. The standard deviation of sample temperatures in the section $\mathrm{c}$ was smaller than that in the section $b$, suggesting that continuous moving and multiple mixing could effectively reduce the temperature variations and improve the RF heating uniformity ${ }^{[18,51]}$.

Table 4 Temperature $\left({ }^{\circ} \mathrm{C}\right)$ of three samples at different section and position (Figure 2) during RF treatments

\begin{tabular}{|c|c|c|c|c|c|c|c|}
\hline \multirow{2}{*}{ Sample } & \multirow{2}{*}{ Measuring section } & \multicolumn{6}{|c|}{ Measurement point (Figure 2) } \\
\hline & & 1 & 2 & 3 & 4 & 5 & 6 \\
\hline \multirow{3}{*}{ Soybean } & a (initial state) & $25.0 \pm 0.2$ & $24.9 \pm 0.1$ & $25.0 \pm 0.2$ & $25.1 \pm 0.1$ & $25.0 \pm 0.1$ & $24.9 \pm 0.1$ \\
\hline & $\mathrm{b}$ (no movement and mixing) & $68.2 \pm 1.7$ & $71.5 \pm 1.8$ & $72.6 \pm 2.1$ & $73.5 \pm 2.3$ & $72.1 \pm 1.9$ & $71.9 \pm 1.8$ \\
\hline & $\mathrm{c}$ (with movement and mixing) & $70.6 \pm 0.8$ & $71.1 \pm 0.9$ & $70.3 \pm 0.6$ & $70.6 \pm 0.7$ & $70.1 \pm 0.5$ & $70.3 \pm 0.6$ \\
\hline \multirow{3}{*}{ Corn } & a (initial state) & $25.0 \pm 0.2$ & $24.9 \pm 0.1$ & $25.0 \pm 0.2$ & $25.0 \pm 0.2$ & $25.1 \pm 0.1$ & $24.9 \pm 0.2$ \\
\hline & $\mathrm{b}$ (no movement and mixing) & $66.0 \pm 2.1$ & $68.5 \pm 2.3$ & $74.3 \pm 2.6$ & $75.2 \pm 3.0$ & $71.2 \pm 2.2$ & $73.7 \pm 2.4$ \\
\hline & $\mathrm{c}$ (with movement and mixing) & $71.8 \pm 1.5$ & $72.9 \pm 1.9$ & $71.0 \pm 1.5$ & $71.7 \pm 1.4$ & $70.2 \pm 1.3$ & $70.6 \pm 1.4$ \\
\hline \multirow{3}{*}{ Peanut } & a (initial state) & $24.9 \pm 0.1$ & $25.0 \pm 0.2$ & $25.0 \pm 0.2$ & $25.1 \pm 0.2$ & $25.0 \pm 0.2$ & $24.9 \pm 0.1$ \\
\hline & $\mathrm{b}$ (no movement and mixing) & $67.0 \pm 2.5$ & $69.8 \pm 2.6$ & $78.2 \pm 3.2$ & $78.7 \pm 3.6$ & $71.6 \pm 2.7$ & $75.4 \pm 2.9$ \\
\hline & $\mathrm{c}$ (with movement and mixing) & $72.1 \pm 1.9$ & $74.0 \pm 2.1$ & $71.3 \pm 1.8$ & $71.9 \pm 1.9$ & $70.0 \pm 1.6$ & $70.6 \pm 1.5$ \\
\hline
\end{tabular}

\subsection{Heating uniformity after RF heating}

Table 5 provides a detailed comparison of the temperature distribution and heating uniformity index values in RF treated three samples under different operational conditions and positions in the screw conveyor. The standard variations after RF heating were better in small particle size samples than in large ones with the same operating condition and position. Movement and mixing in the sections of $b$ and $c$ under RF treatments improved the heating uniformity due to reduced uniformity index values ${ }^{[26]}$. Similarly, movement and mixing in the sections of $\mathrm{c}$ and $\mathrm{d}$ after RF heating also reduced the standard deviation of average sample temperature and uniformity index values, which indicated that the heating uniformity was improved by movement and mixing after RF treatments via the conveyor ${ }^{[43]}$. The similar trend could be found in mixed samples reported by other researchers ${ }^{[11,25,26,48]}$. Therefore, the screw conveyor could effectively improve RF heating uniformity due to continuous movement and mixing without interrupting heating processes.

Table 5 Comparisons of the temperature and heating uniformity index (mean \pm SD over 3 replicates) of three samples at different positions using various operational conditions

\begin{tabular}{|c|c|c|c|c|}
\hline \multirow[b]{2}{*}{ Sample } & \multicolumn{4}{|c|}{ Average temperature $/{ }^{\circ} \mathrm{C}$} \\
\hline & $\begin{array}{c}\mathrm{a} \\
\text { (initial state) }\end{array}$ & $\begin{array}{c}\mathrm{b} \\
\text { (no movement and mixing) }\end{array}$ & $\begin{array}{c}\mathrm{c} \\
\text { (with movement } \\
\text { and mixing) }\end{array}$ & $\begin{array}{c}\mathrm{d}^{*} \\
\text { (with movement and mixing } \\
\text { in Figure 1) }\end{array}$ \\
\hline Soybean & $25.0 \pm 0.1 \mathrm{~B}^{* *}$ & $71.2 \pm 4.8 \mathrm{~A}$ & $70.6 \pm 1.4 \mathrm{~A}$ & $70.2 \pm 0.8 \mathrm{~A}$ \\
\hline Corn & $25.0 \pm 0.1 \mathrm{~B}$ & $72.3 \pm 5.7 \mathrm{~A}$ & $71.2 \pm 1.5 \mathrm{~A}$ & $70.5 \pm 1.1 \mathrm{~A}$ \\
\hline \multirow[t]{2}{*}{ Peanut } & $25.0 \pm 0.1 \mathrm{~B}$ & $73.6 \pm 6.9 \mathrm{~A}$ & $71.6 \pm 2.5 \mathrm{~A}$ & $70.8 \pm 1.7 \mathrm{~A}$ \\
\hline & & & Uniformity index & \\
\hline Soybean & - & $0.106 \pm 0.002 \mathrm{~A}$ & $0.031 \pm 0.002 \mathrm{~B}$ & $0.021 \pm 0.001 \mathrm{C}$ \\
\hline Corn & - & $0.118 \pm 0.006 \mathrm{~A}$ & $0.038 \pm 0.002 \mathrm{~B}$ & $0.025 \pm 0.002 \mathrm{C}$ \\
\hline Peanut & - & $0.139 \pm 0.008 \mathrm{~A}$ & $0.053 \pm 0.004 \mathrm{~B}$ & $0.032 \pm 0.003 \mathrm{C}$ \\
\hline
\end{tabular}

Note: $*$ The temperature of position d was measured by thermal imaging camera in a plastic container (Figure 4$) ; * *$ Different upper case letters indicate that means are significantly different at $p=0.05$ under different conditions.

\section{Conclusions}

$\mathrm{RF}$ heated soybean, corn and peanut in the screw conveyor resulted in the optimal heating rates of $5.6^{\circ} \mathrm{C} / \mathrm{min}, 5.7^{\circ} \mathrm{C} / \mathrm{min}$ and $5.8^{\circ} \mathrm{C} /$ min under the selected electrode gaps of $13 \mathrm{~cm}, 14 \mathrm{~cm}$ and
$14 \mathrm{~cm}$, respectively. Compared with the stationary condition, the variations between the highest and lowest sample temperatures in the screw conveyor were clearly reduced regardless of soybeans, corn, and peanut. The standard deviation of average temperature and heating uniformity index value for the three samples were also 
significantly reduced using the screw conveyor due to its stable, continuous, uninterrupted sample movement and mixing. This experimental study on designing a small-scale screw conveyor could provide a new and effective method to improve RF heating uniformity and help to promote further practical applications of RF treatments in the food processing industry. Further research is needed to optimize structure of the screw conveyor and evaluate product quality after RF treatments with the required shelf life.

\section{Acknowledgements}

This research was conducted in the College of Mechanical and Electronic Engineering, Northwest A\&F University, and supported by research grants from National Key R\&D Program of China (2016YFD0401000). The authors gratefully thank to Lihui Zhang, Shuang Zhang, Liang Zhao, Teng Cheng, Bo Zhang, Xiaoxi Kou, Zhi Huang and Rui Li for their helps and suggestions in conducting experiments.

\section{[References]}

[1] Koral T. Radio frequency heating and post-baking. Biscuit World Issue, 2004; 7(4): 1-6.

[2] Palazoğlu T K, Coskun Y, Kocadağli T, Gokmen V. Effect of radio frequency postdrying of partially baked cookies on acrylamide content, texture, and color of the final product. Journal of Food Science, 2012; 77(5): E113-E117.

[3] Laycock L, Piyasena P, Mittal G S. Radio frequency cooking of ground, comminuted and muscle meat products. Meat Science, 2003; 65(3): 959-965.

[4] Farag K W, Duggan E, Morgan D J, Cronin D A, Lyng J G. A comparison of conventional and radio frequency defrosting of lean beef meats: Effects on water binding characteristics. Meat Science, 2009; 83(2): 278-284.

[5] Marra F, Zhang L, Lyng J G. Radio frequency treatment of foods: Review of recent advances. Journal of Food Engineering, 2009; 91(4): 497-508.

[6] Lee N H, Li C, Zhao X, Park M J. Effect of pretreatment with high temperature and low humidity on drying time and prevention of checking during radio-frequency/vacuum drying of Japanese cedar pillar. Journal of Wood Science, 2010; 56(1): 19-24.

[7] Wang Y, Zhang L, Johnson J, Gao M, Tang J, Powers J R, et al. Developing hot air-assisted radio frequency drying for in-shell macadamia nuts. Food and Bioprocess Technology, 2014; 7(1): 278-288.

[8] Gao M, Tang J, Villa-Rojas R, Wang Y, Wang S. Pasteurization process development for controlling Salmonella in in-shell almonds using radio frequency energy. Journal of Food Engineering, 2011; 104(2): 299-306.

[9] Kim S Y, Sagong H G, Choi S H, Ryu S, Kang D H. Radio-frequency heating to inactivate Salmonella Typhimurium and Escherichia coli O157:H7 on black and red pepper spice. International Journal of Food Microbiology, 2012; 153(1-2): 171-175.

[10] Ling B, Ouyang S, Wang S. Radio-frequency treatment for stabilization of wheat germ: Storage stability and physicochemical properties. Innovative Food Science and Emerging Technologies, 2019; 52: 158-165.

[11] Hou L, Ling B, Wang S. Development of thermal treatment protocol for disinfesting chestnuts using radio frequency energy. Postharvest Biology and Technology, 2014; 98: 65-71.

[12] Piyasena P, Dussault C, Koutchma T, Ramaswamy H S, Awuah G B. Radio frequency heating of foods: Principles, applications and related properties - A review. Critical Reviews in Food Science and Nutrition, 2003; 43(6): 587-606

[13] Liu Y H, Yang B L, Mao Z H. Radio frequency technology and its applicationin agro-product and food processing. Transactions of the CSAM, 2010; 41(8): 115-120. (in Chinese)

[14] Jiao Y, Tang J, Wang S, Koral T. Influence of dielectric properties on the heating rate in free-running oscillator radio frequency systems. Journal of Food Engineering, 2014; 120: 197-203.

[15] Wang K, Zhu H, Chen L, Li W, Wang S. Validation of top electrode voltage in free-running oscillator radio frequency systems with different moisture content soybeans. Biosystems Engineering, 2015; 131: 41-48.

[16] Zhou H, Guo C, Wang S. Performance comparison between the free running oscillator and $50 \Omega$ radio frequency systems. Innovative Food
Science \& Emerging Technologies, 2017; 39: 171-178.

[17] Jiao Y, Tang J, Wang S. A new strategy to improve heating uniformity of low moisture foods in radio frequency treatment for pathogen control. Journal of Food Engineering, 2014; 141: 128-138.

[18] Chen L, Wang K, Li W, Wang S. A strategy to simulate radio frequency heating under mixing conditions. Computers and Electronics in Agriculture, 2015; 118: 100-110.

[19] Huang Z, Zhu H, Yan R, Wang S. Simulation and prediction of radio frequency heating in dry soybeans. Biosystems Engineering, 2015; 129: 34-47.

[20] Fu Y C. Fundamentals and industrial applications of microwave and radio frequency in food processing. In J. S. Smith, \& Y. H. Hui (Eds.), Food processing: Principles and applications. (pp.79-100), Iowa: Blackwell, 2004.

[21] Wang S, Tiwari G, Jiao S, Johnson J A, Tang J. Developing postharvest disinfestation treatments for legumes using radio frequency energy. Biosystems Engineering, 2010, 105(3): 341-349

[22] Tiwari G, Wang S, Tang J, Birla S L. Computer simulation model development and validation for radio frequency (RF) heating of dry food materials. Journal of Food Engineering, 2011; 105(1): 48-55.

[23] Uyar R, Erdogdu F, Marra F. Effect of load volume on power absorption and temperature evolution during radio-frequency heating of meat cubes: A computational study. Food and Bioproducts Processing, 2014; 92(3): 243-251.

[24] Zhou L, Ling B, Zheng A, Zhang B, Wang S. Developing radio frequency technology for postharvest insect control in milled rice. Journal of Stored Products Research, 2015; 62: 22-31.

[25] Ling B, Hou L, Li R, Wang S. Storage stability of pistachios as influenced by radio frequency treatments for postharvest disinfestations. Innovative Food Science \& Emerging Technologies, 2015; 33: 357-364.

[26] Zheng A, Zhang B, Zhou L, Wang S. Application of radio frequency pasteurization to corn (Zea mays L.): Heating uniformity improvement and quality stability evaluation. Journal of Stored Products Research, 2016; 68: 63-72.

[27] Romano V, Marra F. A numerical analysis of radio frequency heating of regular shaped foodstuff. Journal of Food Engineering, 2008; 84(3): 449-457.

[28] Soto-Reyes N, Temis-Pérez A L, López-Malo A, Rojas-Laguna R, Sosa-Morales M E. Effects of shape and size of agar gels on heating uniformity during pulsed microwave treatment. Journal of Food Science, 2015; 80(5): E1021-1025.

[29] Zhang S, Huang Z, Wang S. Improvement of radio frequency (RF) heating uniformity for peanuts with a new strategy using computational modeling. Innovative Food Science \& Emerging Technologies, 2017; 41:79-89.

[30] Chen J, Lau S K, Chen L, Wang S. Subbiah J. Modeling radio frequency heating of food moving on a conveyor belt. Food and Bioproducts Processing, 2017; 102: 307-319.

[31] Bedane T F, Chen L, Marra F, Wang S. Experimental study of radio frequency (RF) thawing of foods with movement on conveyor belt. Journal of Food Engineering, 2017; 201: 17-25.

[32] Waje S S, Thorat B N, Mujumdar A S. Screw conveyor dryer: Process and equipment design. Drying Technology, 2007; 25(1): 241-247.

[33] Dai J, Grace J R. A model for biomass screw feeding. Powder Technology, 2008; 186(1): 40-55.

[34] Dhenge R M, Washino K, Cartwright J J, Hounslow M J, Salman A D. Twin screw granulation using conveying screws: Effects of viscosity of granulation liquids and flow of powders. Powder Technology, 2013; 238: $77-90$.

[35] Qi F L, Heindel T J, Wright M M. Numerical study of particle mixing in a lab-scale screw mixer using the discrete element method. Powder Technology, 2017; 308: 334-345.

[36] Hu Y, Dai L, Pi Y. Theories and calculation of the auger-type conveyer. Journal of Nanchang University (Engineering and Technology), 2000; 22(4): 29-33, 91. (in Chinese)

[37] Shao X, Wang P. The design and calculation of screw conveyor and its application in pulp and paper industry. China Pulp and Paper Industry, 2013; 34(20): 44-47. (in Chinese)

[38] Liu Y, Li Y, Li F, Wang T. Key factors for the design and manufacture of screw conveyer for the production of PVC. Polyviny Chloride, 2008; 36(7): 36-37.

[39] Orefice L, Khinast J G. DEM study of granular transport in partially filled horizontal screw conveyors. Powder Technology, 2017; 305: 347-356.

[40] Hou L, Ling B, Wang S. Kinetics of color degradation of chestnut kernel 
during thermal treatment and storage. Int J Agric \& Biol Eng, 2015; 8(4): $106-115$.

[41] Wang S, Yue J, Tang J, Chen B. Mathematical modelling of heating uniformity for in-shell walnuts subjected to radio frequency treatments with intermittent stirrings. Postharvest Biology and Technology, 2005; 35(1): 97-107.

[42] Zhou L, Wang S. Verification of radio frequency heating uniformity and Sitophilus oryzae control in rough, brown, and milled rice. Journal of Stored Products Research, 2016; 65: 40-47.

[43] Zhou L, Wang S. Industrial-scale radio frequency treatments to control Sitophilus oryzae in rough, brown, and milled rice. Journal of Stored Products Research, 2016; 68: 9-18.

[44] Wang S, Yue J, Chen B, Tang J. Treatment design of radio frequency heating based on insect control and product quality. Postharvest Biology and Technology, 2008; 49(3): 417-423.

[45] Wang S, Monzon A, Johnson J A, Mitcham E J, Tang J. Industrial-scale radio frequency treatments for insect control in walnuts I: Heating uniformity and energy efficiency. Postharvest Biology and Technology, 2007; 45(2): 240-246.

[46] Jiao S, Johnson J A, Tang J, Wang S. Industrial-scale radio frequency treatments for insect control in lentils. Journal of Stored Products Research, 2012; 48: 143-148.

[47] Pan L, Jiao S, Gautz L, Tu K, Wang S. Coffee bean heating uniformity and quality as influenced by radio frequency treatments for postharvest disinfestations. Transactions of the ASABE, 2012; 55(6): 2293-2300.

[48] Gao M, Tang J, Wang Y, Powers J, Wang S. Almond quality as influenced by radio frequency heat treatments for disinfestation. Postharvest Biology and Technology, 2010; 58(3): 225-231.

[49] Hansen J D, Drake S R, Watkins M A, Heidt M L, Anderson P A, Tang J. Radio frequency pulse application for heating uniformity in postharvest codling moth (Lepidoptera: Tortricidae) control of fresh apples (Malus domestica Borkh). Journal of Food Quality, 2006; 29(5): 492-504.

[50] Yan R, Huang Z, Li R, Zhu H, Ling B, Wang S. Temperature measurement and analysis of postharvest agricultural products associated with thermal disinfestations. Int J Agric \& Biol Eng, 2013; 6(2): 87-94.

[51] Chen L, Wang K, Li W, Wang S. Simulation and validation of radio frequency heating with conveyor movement. Journal of Electromagnetic Waves and Applications, 2015; 30(4): 472-490.

[52] Guo W, Wang S, Tiwari G, Johnson J A, Tang J. Temperature and moisture dependent dielectric properties of legume flour associated with dielectric heating. LWT - Food Science and Technology, 2010; 43(2): 193-201.

[53] Jin Z, Wang S, Han P. Frequency, moisture and temperature-dependent dielectric properties of maize. Journal of China Agricultural University, 2011; 16(4): 141-147. (in Chinese)

[54] Zhang S, Zhou L, Ling B, Wang S. Dielectric properties of peanut kernels associated with microwave and radio frequency drying. Biosystems Engineering, 2016; 145: 108-117. 